University of Nebraska - Lincoln

DigitalCommons@University of Nebraska - Lincoln

$11-2001$

\title{
Enzymological and Radiotracer Studies of lipid Metabolism in the Flight-Capable and Flightless Morphs of the Wing-Polymorphic Cricket, Gryllus firmus
}

Z. Zhao

University of Nebraska - Lincoln

Anthony J. Zera

University of Nebraska - Lincoln, azera1@unl.edu

Follow this and additional works at: https://digitalcommons.unl.edu/bioscizera

Part of the Microbiology Commons

Zhao, Z. and Zera, Anthony J., "Enzymological and Radiotracer Studies of lipid Metabolism in the FlightCapable and Flightless Morphs of the Wing-Polymorphic Cricket, Gryllus firmus" (2001). Anthony Zera Publications. 34.

https://digitalcommons.unl.edu/bioscizera/34

This Article is brought to you for free and open access by the Papers in the Biological Sciences at DigitalCommons@University of Nebraska - Lincoln. It has been accepted for inclusion in Anthony Zera Publications by an authorized administrator of DigitalCommons@University of Nebraska - Lincoln. 
Published in Journal of Insect Physiology 47:11 (November 2001), pp. 1337-1347; doi 10.1016/S0022-1910(01)00123-8

Copyright () 2001 Elsevier Science Ltd. Used by permission. http://www.sciencedirect.com/science/journal/00221910

Submitted March 23, 2001; accepted June 18, 2001; published online October 8, 2001.

\title{
Enzymological and radiotracer studies of lipid metabolism in the flight-capable and flightless morphs of the wing-polymorphic cricket, Gryllus firmus
}

\author{
Z. Zhao and A. J. Zera \\ School of Biological Sciences, University of Nebraska-Lincoln, Lincoln, NE 68588, USA \\ Corresponding author - A. J. Zera, tel 402 472-2768, fax 402 472-2083, email azera@unlserve.unl.edu \\ Permanent address for Z. Zhao - Institute of Zoology, Chinese Academy of Sciences, Beijing, Peoples' Republic of China
}

\begin{abstract}
The flight-capable morph of the wing-polymorphic cricket, Gryllus firmus, exhibited significantly higher activities of each of five lipogenic enzymes compared with the obligately flightless morph on a standard and a high-carbohydrate diet during early adulthood. Similarly, the rate of incorporation of $\left[{ }^{14} \mathrm{C}\right]$-acetate into total lipid was higher in the flight-capable morph during this time. By contrast, activities of lipogenic enzymes and rates of lipid biosynthesis, in general, did not differ between morphs on a low nutrient diet during early adulthood. Differences in lipid biosynthesis account for previously documented differences in lipid reserves between morphs on some, but not all, diets. Results of the present and previous studies indicate that increased lipid biosynthesis in the flight capable morph on standard and high-carbohydrate diets constitutes an important adaptation for flight (production of lipid flight fuel). Lipid biosynthesis is negatively correlated with ovarian growth, and may be an important biochemical component of the trade-off between flight capability and ovarian growth in G. firmus. Morphs also differed in activities of three enzymes of lipid catabolism. However, the extent to which variation in activities of these enzymes between morphs results in variation in lipid catabolism is unclear. Finally, the flight-capable morph had a substantially higher activity of alanine aminotransferase in the fat body. Amino acids may be utilized for lipid biosynthesis or energy production to a greater degree in the dispersing morph compared with the oligately flightless morph. This study is the first to document differences in intermediary metabolism that underlie adaptations of morphs of a dispersal-polymorphic species for flight vs. egg production.
\end{abstract}

Keywords: lipogenesis, lipid, fatty acid synthase, glucose-6-phosphate dehydrogenase, Gryllus, trade-off, wing polymorphism

\section{Introduction}

Flight polymorphism (also called dispersal or wing polymorphism) occurs widely in the Insecta and involves discontinuous variation in a wide variety of traits involved in flight and reproduction (Roff, 1986; Dingle, 1996; Zera and Denno, 1997). One morph contains fully developed wings and flight muscles and is capable of flight. By contrast, one or more morphs have reduced wings and flight-muscles, or reduced flight muscles alone, and cannot fly. Importantly, flight capability is negatively associated with egg production. That is, ovarian growth is substantially faster and egg production is substantially greater in the flightless morph compared with the flight-capable morphs during early adulthood.

Flight polymorphism has been used extensively as a model to investigate a wide variety of issues relating to the evolution, ecology, and physiology of dispersal, reproduction, and the negative interaction (trade-off) between these two important organismal functions. (Harrison, 1988; Roff, 1986; Dingle, 1996; Zera and Denno, 1997; Zera and Harshman, 2001). A number of physiological studies have documented differences between morphs in energetic or endocrine aspects of flight capability and egg production (reviewed in Zera and Denno, 1997; Zera et al., 1998; Zera and Larsen, 2001; Zera and Harshman, 2001). However, almost nothing is known 
about the biochemical or metabolic underpinnings of these physiological differences (Zera et al., 1999).

We have been using the wing-polymorphic cricket, Gryllus firmus, as a model to investigate physiological, biochemical, and molecular bases of adaptations of morphs for dispersal vs. reproduction. An important focus of our studies is the variation in lipid metabolism between morphs (Zera et al., 1994, 1998; Zera and Brink, 2000; Zera and Harshman, 2001; Zera and Larsen, 2001). Lipid is the major flight fuel in species of Gryllus (Zera et al., 1999), as is the case for many other insects, especially orthopterans (Beenakkers et al., 1985; Candy, 1989). The flight-capable morph of G. firmus has significantly greater $(30-40 \%)$ mass-adjusted triglyceride levels than the flightless morph near the end of the first week of adulthood (Zera et al., 1994; Zera and Larsen, 2001). The existence of elevated total lipid and triglyceride stores in the dispersing morph of G. firmus is similar to the situation found in dispersing vs. reproductive phenotypes of other dispersal-polymorphic insects (Uvarov, 1966; Newanze et al., 1976; Gunn and Gatehouse, 1987; Zera et al., 1994). Furthermore, the increased accumulation of lipid in flight-capable G. firmus may have a significant negative impact on ovarian growth, which is substantially lower (50-25\%) relative to that in the flightless morph. These data indicate that the flight-capable morph of G. firmus is programmed to accumulate triglyceride flight fuel at the expense of ovarian growth during early adulthood, while the flightless morph prioritizes ovarian growth over triglyceride accumulation.

Although increased triglyceride accumulation in the flight-capable morph has been documented in three studies of two species of Gryllus (Zera et al., 1994, 1998; Zera and Larsen, 2001), little information is available on the biochemical basis of this phenomenon. Feeding studies have documented that increased lipid in the flight-capable morph is not the consequence of increased lipid intake (i.e., consumption plus assimilation; Zera and Brink, 2000; Rooneem and Zera, unpublished data). These results point to increased lipid biosynthesis or decreased utilization as the most likely causes of the higher lipid levels produced in the flight-capable morph during early adulthood. Here we report on comparisons between morphs of G. firmus with respect to the activities of five key enzymes in lipid biosynthesis, three key enzymes in lipid catabolism, and direct measures of morph-specific rates of de novo lipid biosynthesis. Measurements were performed during the first week of adulthood when the flight-capable morph accumulates a significantly greater quantity of triglyceride, but exhibits substantially reduced ovarian growth, relative to the flightless morphs.

\section{Materials and methods}

\subsection{Background on G. firmus: morphs, stocks, and rearing conditions}

Gryllus firmus, the sand cricket, occurs in the southeastern United States as a long-winged (LW) morph, some of which are capable of flight, or as a short-winged (SW) morph that is obligatory flightless (Veazy et al., 1976; Zera et al., 1997). Except in a few rare cases, all SW females molt into adults with white, non-functional, underdeveloped flight muscles. All LW females initially have fully-developed, functional (pink) flight muscles at or shortly after the adult molt. Individuals with functional flight muscles are denoted as LW(f). Upon onset of ovarian growth, some LW(f) individuals histolyze their flight muscles thus becoming flightless-denoted LW(h) (Zera et al., 1997).

The G. firmus females used in the present study were taken from a pair of lines derived from the 18th generation of an artificial selection experiment. Details of the selection experiment can be found in Zera and Huang (1999) and Zera and Cisper (2001). All LW(f) and LW(h) females were taken from one line selected for the LW morph, while all SW females were taken from a line of the same block (same selection trial) that had been selected for the SW morph. The LW-selected line contained $89 \%$ LW females, while the SW-selected line contained $86 \%$ SW females during generation 18. Both lines were raised under the same environmental conditions. Briefly, crickets were reared at $28^{\circ} \mathrm{C}$ under a 16L:8D photoperiod, at a density of 80 and 40 crickets per 10 gallon aquarium during the penultimate and last stadium, respectively. Crickets were switched from the standard 'dry' diet to the standard 100\% wet diet - the same components as the dry diet but made up in $2.5 \%$ aqueous agar; see Zera and Larsen (2001) for exact composition of diets - during the penultimate stadium. Crickets used for experiments were checked for molting at $24 \mathrm{~h}$ intervals and equal numbers of newly molted males and females were raised at a density of 4-6 per 1 gallon plastic box or 8-12 per 3-gallon plastic box without oviposition material. By day 5, the ovaries of the flightless, SW morph are 2-4 times as heavy as those of the flight-capable LW(f) morph (Cisper et al., 2000; Zera and Brink, 2000; Zera and Larsen, 2001). These differences in ovarian growth between morphs are typical of those of other dispersal-polymorphic insect species (Zera and Denno, 1997). Ovarian growth under these conditions does not differ statistically from that of mated females allowed to oviposit eggs (Zera, unpublished data).

Enzyme activities and rates of lipid biosynthesis were studied on day 0 (day of molt) and day 5 of adulthood. Day 5 was chosen because this is the period of time during which there is a dramatic trade-off between ovarian 
growth and accumulation of triglyceride reserves in the LW(f) and SW morphs (Zera and Larsen, 2001). Day 0 was chosen as a baseline, to determine rates of biosynthesis and enzyme activities prior to the occurrence of the trade-off mentioned above.

To determine the extent to which differences between morphs in enzyme activities and rates of lipid biosynthesis were contingent upon diet, comparisons were made between morphs fed one of three diets during adulthood. These are the same diets that were used in our prior study of lipid reserves in morphs of G. firmus (Zera and Larsen, 2001), which forms the basis for the present study. All juveniles were raised on the standard diet (termed '100\%' diet), which had been used in earlier feeding studies (Mole and Zera, 1993; Zera et al., 1998; Zera and Brink, 2000). All individuals were fed this diet up to and including the penultimate and last juvenile stadia. Starting on the day of adult molt, one group of adults was fed this same diet. A second group of adults was fed a low nutrient diet in which $75 \%$ of the dry mass of the high-nutrient diet had been replaced with non-nutritive cellulose (termed '25\%' diet). Growth in two Gryllus species, G. assimilis and G. firmus, is substantially reduced on this diet (Zera et al., 1998; Rooneem and Zera, unpublished data). A third group of crickets was fed a high-carbohydrate diet starting on the first day of adulthood. In this diet $67 \%$ of the cellulose of the low nutrient diet was replaced with sucrose (termed ' $25 \%+$ sucrose' or 'high carbohydrate' diet). A high carbohydrate diet was used since many studies have shown that rates of lipogenesis and activities of lipogenic enzymes are strongly affected by the quantity of carbohydrate in the diet (Geer and Perille, 1977; Downer, 1985). All diets had the same dry mass and water content.

\subsection{Fat body homogenization}

Enzyme activities were measured in fat body, the major organ of lipid metabolism in insects (Downer, 1985). Approximately 3-5 mg of fat body were removed from an adult female cricket, rinsed briefly in MOPS (3-[Nmorpholino]propanesulfonic acid) buffer $(0.1 \mathrm{M}$, pH either 7.0 or 8.0 , depending upon the assay) to remove hemolymph proteins, placed in $500 \mu l$ of MOPS buffer, and sonicated for a few seconds. For preparations used to measure activities of the mitochondrial enzymes 3hydroxy-CoA dehydrogenase (HOAD), B-ketothiolase (KT), or carnitine palmitoyl transferase (CPT), MOPS buffer contained $0.2 \% \mathrm{v} / \mathrm{v}$ Triton X-100 to help solubilize these enzymes (as suggested by Joanisse and Storey, 1996). Crude homogenates of enzymes excluding CPT, HOAD, and KT were centrifuged at $3300 \mathrm{~g}$ for $5 \mathrm{~min}$, and supernatants were used in the enzyme assays. Background studies documented that essentially all activity of enzymes except HOAD, KT, and CPT were in the supernatant $(<10 \%$ of total activity in re- suspended pellet). For CPT, HOAD, and KT, significant amounts of enzyme activity were found in both the resuspended pellet and the supernatant, even with the inclusion of Triton X-100 in the homogenizing buffer. Thus activities of these three enzymes were measured using uncentrifuged homogenates as described in Zera et al. (1999).

For each enzyme, background experiments documented that uncentrifuged or centrifuged homogenates lost no activity over an $8 \mathrm{~h}$ period when kept undiluted on ice. Homogenates were never used for assays longer than this period. Backgound studies also documented the conditions under which enzyme activity was proportional to homogenate (i.e. enzyme) concentration or time (i.e., initial rates). All assays were conducted under these conditions. Finally, in all assays, extensive background experiments were conducted to check for absorbance changes due to factors other than the activity of the enzyme being assayed (e.g. NADH oxidation in the absence of substrate for dehydrogenase assays).

\subsection{Enzymes assays}

In this study, a diverse set of lipid anabolic and catabolic enzymes were studied (see Section 4). Reaction rates were measured by adding $20 \mu \mathrm{l}$ of fat body homogenate to assay solutions, described below, giving a final volume of $500 \mu \mathrm{l}$. Assay mixtures were preincubated at $28^{\circ} \mathrm{C}$ in a thermoset temperature control unit and rates measured using a Response spectrophotometer. To avoid production of $\mathrm{NAD}(\mathrm{P}) \mathrm{H}$ inhibitors, $\mathrm{NADH}$ or NADPH solutions were made up from dry powder immediately prior to measuring enzyme activities and were used within $4 \mathrm{~h}$. Unless otherwise stated, reaction rates were determined by following the change in absorbance at $339 \mathrm{~nm}$.

The following assay solutions were used:

1. $\mathrm{NADP}^{+}$-Isocitrate dehydrogenase (NADP+-IDH; E.C. 1.1.1.42): $6.0 \mathrm{mM}$ isocitrate, $4 \mathrm{mM} \mathrm{MgCl} 2,0.4 \mathrm{mM}$ NADP, $50 \mathrm{mM}$ MOPS buffer, pH 8.0 (modified from Storey and Bailey, 1978).

2. Glucose-6-phosphate dehydrogenase (G-6-PDH; E.C. 1.1.1.49): $0.4 \mathrm{mM}$ NADP, $7 \mathrm{mM} \mathrm{MgCl}{ }_{2}, 6.3 \mathrm{mM}$ glucose-6-phosphate, 50 mM MOPS buffer, $\mathrm{pH} 8.0$ (modified from Storey and Bailey, 1978).

3. Malic enzyme (ME; E.C. 1.1.1.40): 0.4 mM NADP, $0.8 \mathrm{mM}$ $\mathrm{MnCl}_{2}, 2 \mathrm{mM}$ Na-malate, $50 \mathrm{mM}$ MOPS buffer, $\mathrm{pH} 8.0$ (modified from Storey and Bailey, 1978).

4. Fatty acid synthase (FAS): $1 \mathrm{mM}$ DTT, $1 \mathrm{mM}$ EDTA, $0.03 \mathrm{mM}$ acetyl CoA, $0.05 \mathrm{mM}$ malonyl CoA, $0.15 \mathrm{mM}$ NADPH, 50 mM MOPS buffer, pH 7.0 (modified from Buckner and Kolattukudy, 1976).

5. ATP-citrate lyase (ACL; E.C. 4.1.3.8): $10 \mathrm{mM} \mathrm{MgCl}_{2}, 0.3 \mathrm{mM}$ coenzyme A, $10 \mathrm{mM}$ DTT, $21 \mathrm{mM} \mathrm{K}$-citrate, $5 \mathrm{mM}$ ATP, 1 unit MDH, 0.14 mM NADH, 50 mM TAPS (3-[N-tris-(Hy- 
droxymethyl) methyl-amino]-propanesulfonic acid) buffer, pH 8.7 (modified from Storey and Bailey, 1978).

6. 3-Hydroxy-CoA dehydrogenase (HOAD; E.C. 1.1.1.35): $0.1 \mathrm{mM}$ acetoacetyl CoA, $0.15 \mathrm{mM}$ NADH, $1 \mathrm{mM} \mathrm{KCN}, 100 \mathrm{mM}$ MOPS buffer, pH 7.0 (modified from Beenakkers, 1969).

7. B-Ketothiolase (KT; E.C. 2.3.1.9): $0.12 \mathrm{mM}$ coenzyme A, $0.07 \mathrm{mM}$ acetoacetyl-Co-A; $50 \mathrm{mM}$ MOPS, pH, 7.0; absorbance measured at $303 \mathrm{~nm}$ (modified from Joanisse and Storey, 1996).

8. Carnitine palmitoyl transferase (CPT; E.C. 2.3.1.21): $0.25 \mathrm{mM}$ 5,5' dithio-bis[2-nitrobenzoic acid] (DTNB), $1.25 \mathrm{mM} \mathrm{L-car-}$ nitine, $0.04 \mathrm{mM}$ palmitoleoyl-CoA, $100 \mathrm{mM}$ MOPS buffer, $\mathrm{pH}$ 8.0, measured at $412 \mathrm{~nm}$ (Bieber et al., 1972).

9. Alanine aminotransferase (AAT; E.C. 2.6.1.2): $100 \mathrm{mM}$ alanine, $0.18 \mathrm{mM}$ NADH, $0.11 \mathrm{mM}$ pyridoxyl phosphate, $15 \mathrm{mM}$ 2-oxoglutaric (a-ketoglutaric) acid, 50 mM MOPS, pH 7.3 (modified from Bergmeyer, 1974).

10. Soluble protein: Bicinchoninic acid assay using bovine serum albumen (fraction V) as the standard (Stoscheck, 1990).

\subsection{Incorporation of $\left[{ }^{14} \mathrm{C}\right]$-acetate into lipid}

Female G. firmus were injected with $2 \mu \mathrm{l}$ of 500,000 DPM of $\left[1-{ }^{14} \mathrm{C}\right]-\mathrm{Na}$-acetate $(2.0 \mathrm{GBq} / \mathrm{mmol} ; 54.7 \mathrm{mCi} /$ $\mathrm{mmol})$ dissolved in sterile saline $(0.9 \% \mathrm{NaCl})$. Crickets had been unfed for $4 \mathrm{~h}$ prior to injection. After injection, crickets were returned to their containers and were kept at $28^{\circ} \mathrm{C}$. Background experiments documented that the rate of incorporation of radiolabeled acetate into total lipid is linear with time up to $8 \mathrm{~h}$ post injection (Figure 1). At $7 \mathrm{~h}$ post injection crickets were placed into a tube containing $5 \mathrm{ml}$ of chloroform/methanol $(2: 1, \mathrm{v} / \mathrm{v})$, and were homogenized, centrifuged, and the mixture filtered through Whatman \#1 paper. The residue was

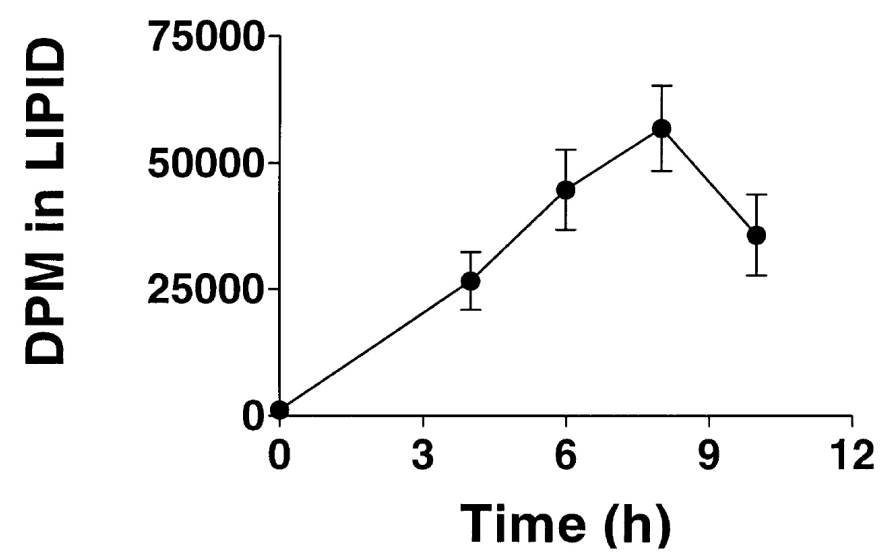

Figure 1. Time course of incorporation of $\left[{ }^{14} \mathrm{C}\right]$-acetate into total lipid in G. firmus. Each point represents the mean $( \pm S E M)$ DPM in total lipid extracted from three crickets. See Section 2 for experimental details. returned to the tube and the process was repeated two more times using the same filter paper and tube used to collect the first extract. The total extract was washed three times with $1 / 4$ its volume with $0.88 \% \mathrm{KCl}$ in water. Three washes as opposed to the standard single $\mathrm{KCl}$ wash (Zera et al., 1994), were necessary to completely remove traces of non-lipid radiolabeled compounds dissolved in the chloroform/methanol. The extracts were placed in scintillation vials, the solvent was allowed to evaporate overnight, $3 \mathrm{ml}$ of Ready-Safe scintillation fluid was added, and DPM were quantified by liquid scintillation spectrometry (1219 Rackbeta; Wallac).

\subsection{Total fat body mass}

To determine the total fat body content in the thorax and abdomen of morphs of G. firmus on day 5 of adulthood on various diets, all fat bodies were removed and their wet mass determined. Prior to dissection, the wet mass of the cricket was obtained.

\subsection{Statistical analyses}

Specific activities of enzymes (activities standardized to protein concentration), or DPM of acetate incorporated into total lipid, were analyzed on either day 0 or day 5 by factorial ANOVA with MORPH and DIET as categorical variables. Differences in activities or DPM between days 0 and 5 for each morph on each diet were also analyzed by ANOVA. Variation between morphs in fat body wet mass was analyzed by ANCOVA with total body wet mass as the covariate.

\section{Results}

\subsection{Specific activities of lipid biosynthetic enzymes}

Enzyme activities in fat bodies of the LW(f) and SW morphs, the main foci of the present study, will first be presented. On the first day of adulthood, activities of the three NADPH-producing enzymes were low and either did not differ significantly between LW(f) and SW female G. firmus (IDH and ME), or differed only slightly [G-6-PDH; Figure 2). On the standard diet, activities of each of these three enzymes rose three- to six-fold between days 0 and 5 ( $P<0.005$ for each of five ANOVAs). The one exception was ME in the SW morph which exhibited no change between these two days (ANOVA, $P=0.63$ ). On day 5 , activities were significantly higher in the LW(f) vs. the SW morph for G-6-PDH (two-fold), IDH (1.6-fold), and ME (four-fold, Figure 2). In a similar manner, IDH, ME, and G-6-PDH activities rose two- to eight-fold between day 0 and day 5 for each morph on the high-carbohydrate $(25 \%+$ sucrose $)$ diet $(P<0.002$ for five ANOVAs; $P<0.025$ for ME activities in the SW morph). On day 5, fat-body activities were nearly two- 

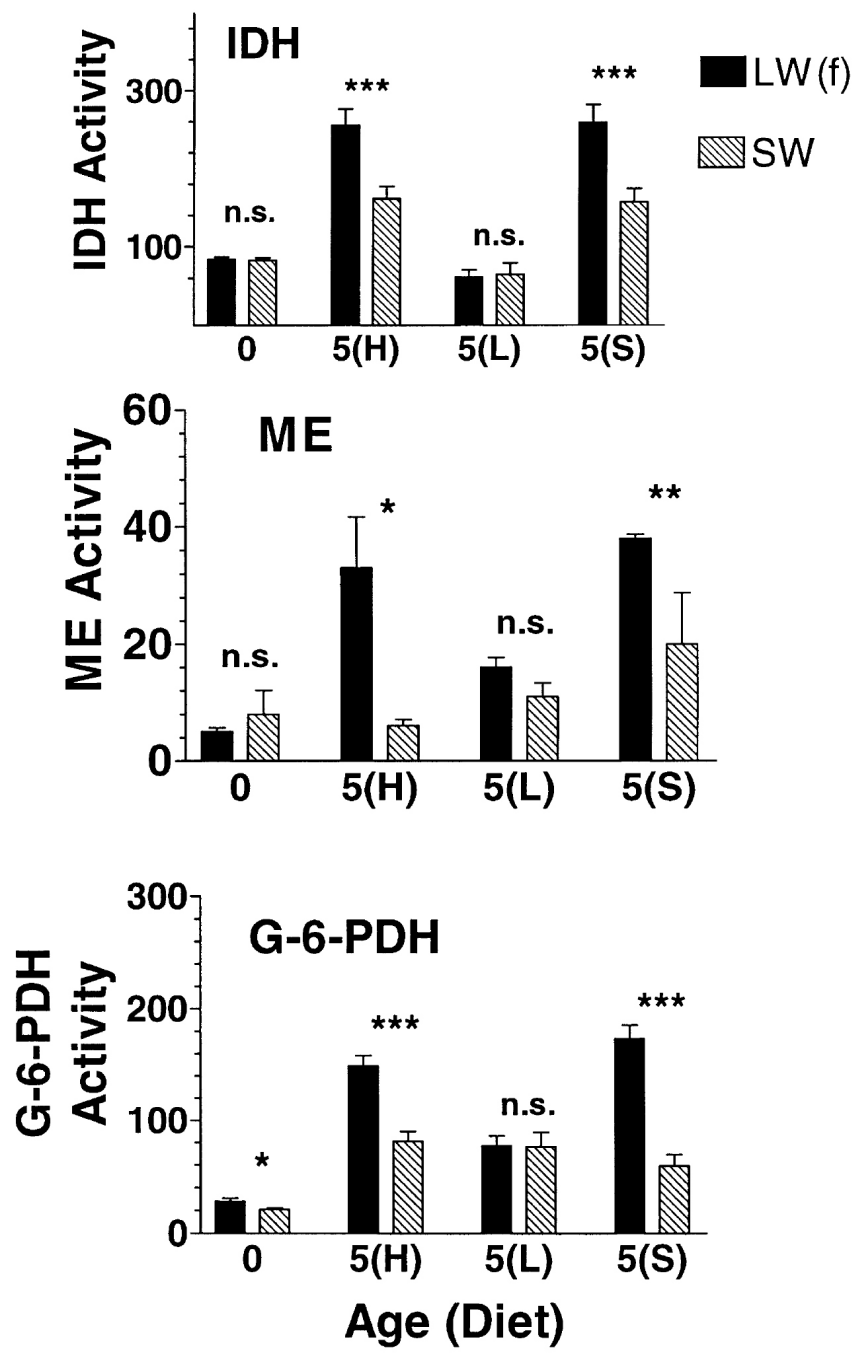

Figure 2. Specific activities (means \pm SEM) of NADPH-producing enzymes (IDH, ME, and G-6-PDH). Activities were measured in homogenates of fat bodies of flight capable [LW(f)] and obligately flightless (SW) morphs of G. firmus fed various diets on days 0 and 5 of adulthood. Numbers on the $x$-axis refer to days after molt to adulthood while letters refer to diets on which crickets were fed $(H=100 \%, L=25 \%, S=25 \%+$ sucrose diets; see Section 2 for additional details on diets). Symbols above bars represent results of $t$-tests of activities of $\mathrm{LW}(\mathrm{f})$ vs. SW morphs on that day $/$ diet; n.s. $=$ non significant; ${ }^{*}=P$ $<0.05,{ }^{* *}=P<0.025,{ }^{* *}=P<0.005$. Specific activities are in units of $\mathrm{nmol} / \mathrm{min} / \mathrm{mg}$ protein. Sample size for each mean was as follows: IDH and G-6-PDH, $N=9-10$, except for the $25 \%$ diet where $N=5$; ME, $N=3-5$.

to three-fold higher in the $\mathrm{LW}(\mathrm{f})$ vs. the SW morph for G-6-PDH, IDH and ME. By contrast, enzyme activities exhibited a different pattern of variation between morphs and days on the $25 \%$ diet (Figure 2). In general, enzyme activities rose much less between day 0 and day 5 on this diet than on the standard or high carbohydrate diets. For example, IDH activities did not differ between these two days for either morph $(P>0.2)$, and ME activities did not differ for the SW morph $(P=$ 0.17 ), and only differed marginally for the $L W(f)$ morph
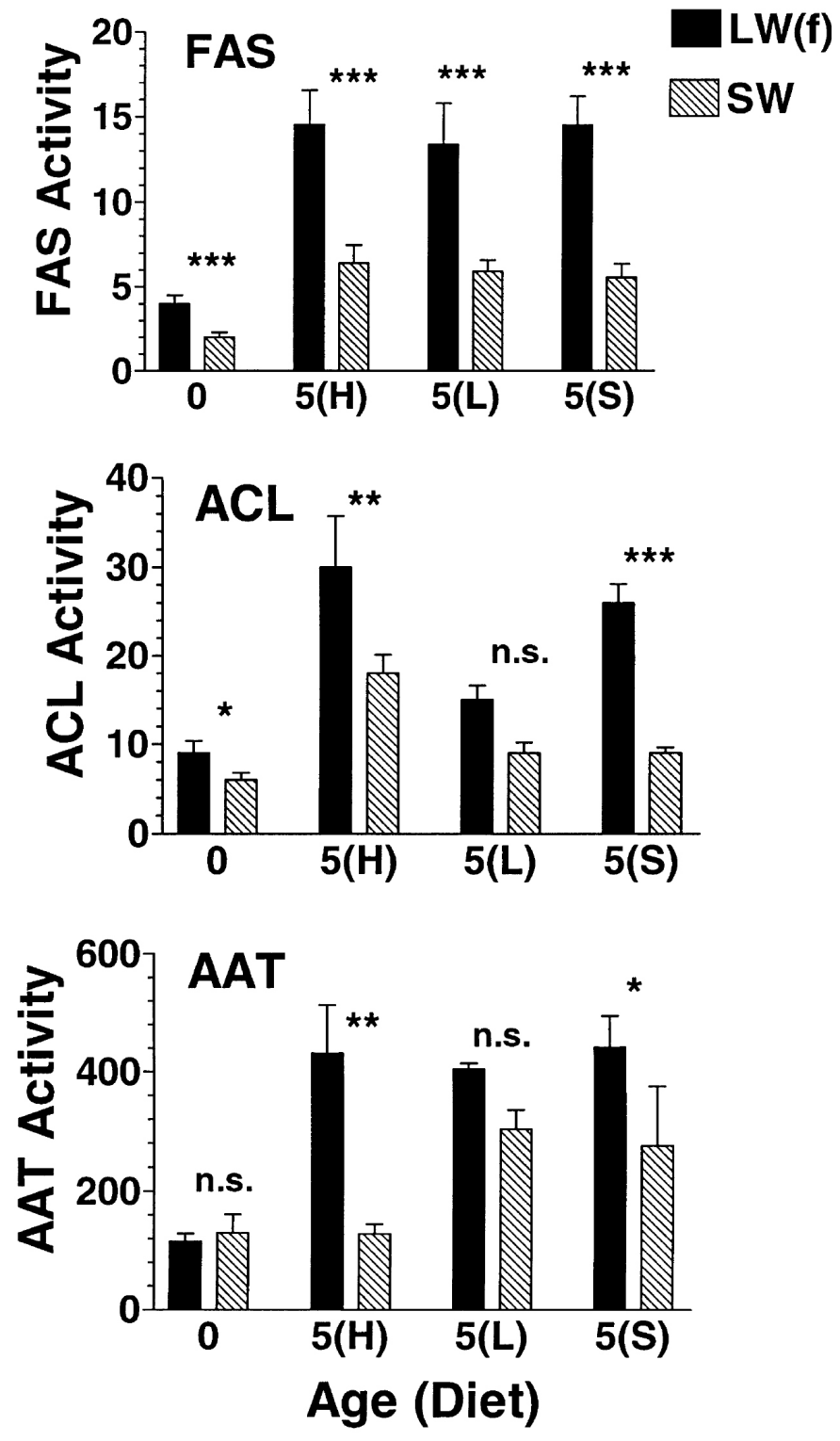

Figure 3. Specific activities (mean \pm SEM) of lipogenic enzymes (FAS and ACL), and an amino-acid-metabolizing enzyme (ATT). Activities were measured in homogenates of fat bodies of flight capable [LW(f)] and obligately flightless (SW) morphs of G. firmus fed various diets on days 0 and 5 of adulthood. See legend of Figure 1 for explanation of numbers and letters on the $x$-axis and symbols above bars. Specific activities are in units of $\mathrm{nmol} / \mathrm{min} / \mathrm{mg}$ protein. Sample size for each mean was as follows: FAS and ACL, $N=7-10$; AAT, $N=3-5$

$(P=0.03)$. On day 5 on the $25 \%$ diet, morphs did not differ significantly in activities of any of the three enzymes (Figure 2).

In general, specific activities of ACL and FAS exhibited a similar pattern of variation between morphs, diets and days as did the NADPH-producing enzymes (Figure 3). Like IDH, ME and G-6-PDH, specific activities of ACL and FAS were low on day 0 and rose significantly ( $\sim$ three-fold) between day 0 and day 5 for each morph on the $100 \%$ diet $(P<0.01$ for each of four ANO- 


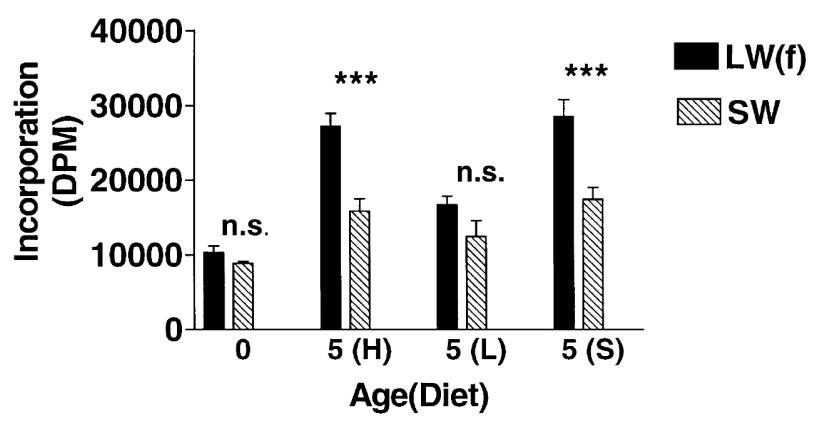

Figure 4. Incorporation of $\left[{ }^{14} \mathrm{C}\right]$-acetate into total lipid during a $7 \mathrm{~h}$ period in flight-capable [LW(f)] and flightless (SW) morphs of G. firmus. Numbers on the $x$-axis refer to days after molt to adulthood while letters refer to diets on which crickets were fed (see legend of Figure 1). Results of statistical analyses are denoted above bars (see legend of Figure 1). Each mean was based on a sample of 7-12 individuals.

VAs), and on the $25 \%+$ sucrose diet $(P<0.025$ in each of three ANOVAs). The one exception was ACL in the SW morph whose activities did not differ between days 0 and 5 on the high sucrose diet (ANOVA, $P=0.29$ ). In contrast to the NADPH-producers, FAS activities were also significantly higher on day 5 vs. day 0 on the $25 \%$ diet for each morph $(P<0.025$ for each ANOVA), while ACL activities did not differ between these two days in either morph [LW(f): $P=0.06$; SW: $P=0.29]$. Most importantly, ACL activities were significantly higher in the $\mathrm{LW}(\mathrm{f})$ vs. the SW morph on day 5, on the $100 \%$ diet (1.6-fold higher), on the $25 \%+$ sucrose diet (three-fold higher), but not on the $25 \%$ diet (1.8-fold higher, Figure $3)$. FAS activities were significantly ( two-fold) higher in the $L W(f)$ compared with the SW morph on day 5 on each diet (Figure 3).

\section{2. $\left[{ }^{14} \mathrm{C}\right]$-acetate incorporation}

The in vivo rate of incorporation of ${ }^{14} \mathrm{C}$-acetate into total lipid differed between morphs, diets and days similar to variation in activities of lipogenic enzymes (Figure 4). Incorporation rates were virtually identical for LW(f) and SW morphs on day zero (Figure 4). However, rates rose 1.7- to 2.8-fold from day 0 to day 5 and were significantly higher in the LW(f) compared with the SW morph on day 5 on both the $100 \%$ diet and on the $25 \%+$ sucrose diet. Like the activities of most of the lipogenic enzymes, acetate incorporation rates did not differ between the morphs on day 5 on the $25 \%$ diet. Furthermore, incorporation rates increased less (1.3- to 1.5-fold) from day 0 to day 5 in either morph on the $25 \%$ diet than they did on the other two diets.

\subsection{Specific activities of enzymes of lipid oxidation}

Activities of three enzymes involved in lipid oxidation, HOAD, KT, and CPT, were similar in LW(f) and SW morphs on the day of adult emergence (Figure 5), as was
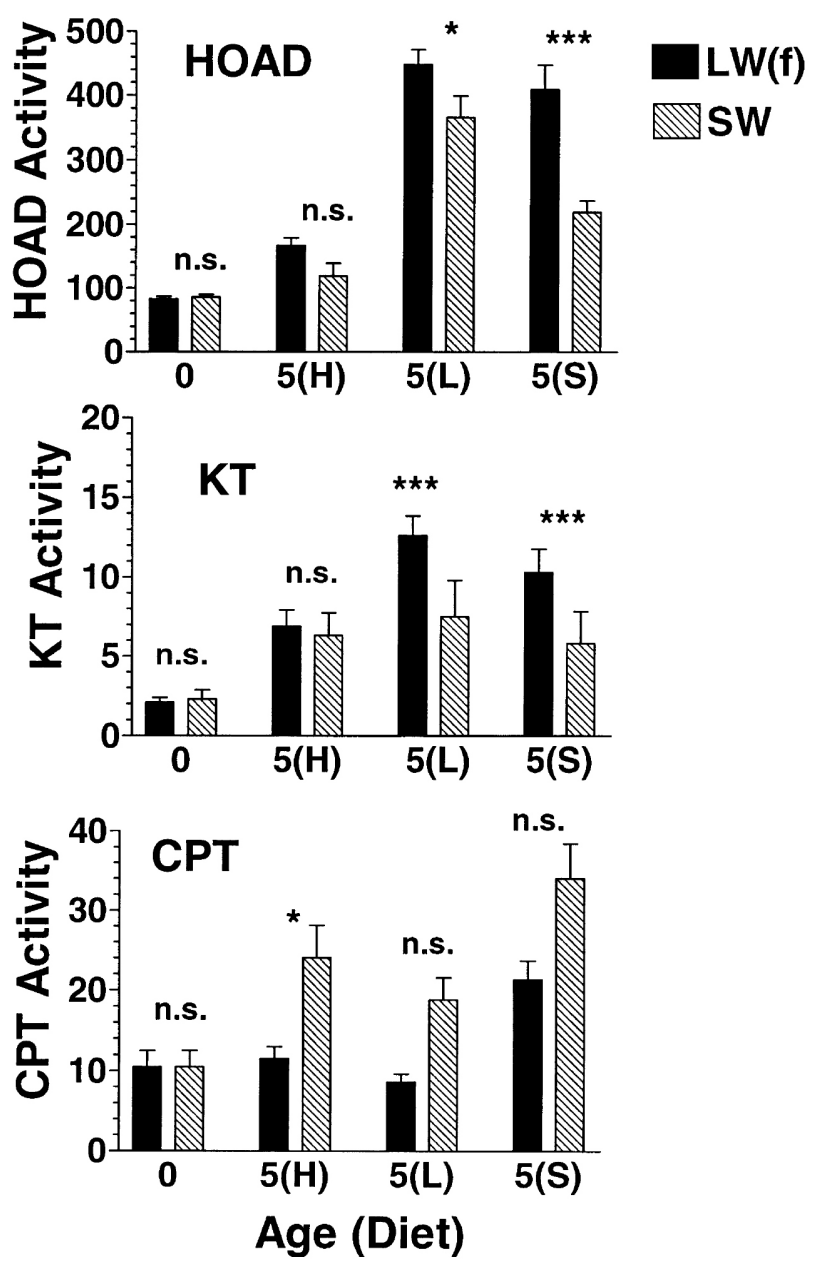

Figure 5. Specific activities (mean \pm SEM) of lipid oxidizing enzymes (HOAD, KT, and CPT). Activities were measured in homogenastes of fat bodies of flight capable [LW(f)] and obligately flightless (SW) morphs of G. firmus fed various diets, on days 0 and 5 of adulthood. Numbers on the $x$-axis refer to days after molt to adulthood while letters refer to diets on which crickets were fed (see legend of Figure 1). Results of statistical analyses are denoted above bars (see legend of Figure 1). Specific activities are in units of $\mathrm{nmol} / \mathrm{min} / \mathrm{mg}$ protein. Means were based on assays of 5-11 individuals, except for CPT on day 0 , where the sample size was four.

the case for activities of most lipogenic enzymes. However, differences between the morphs in activities of oxidative enzymes on other days and diets were unlike those of lipogenic enzymes. For example, in contrast to the biosynthetic enzymes, HOAD and KT specific activities did not differ significantly between morphs on the $100 \%$ diet, were higher on the $25 \%$ diet than on the $100 \%$ diet, and were significantly higher in the $\operatorname{LW}(\mathrm{f})$ vs. the SW morph on the $25 \%$ diet (Figure 5). Like the biosynthetic enzymes, activities were higher in the LW(f) compared with the SW morph for HOAD and for KT on the $25 \%+$ sucrose diet. Finally, CPT activities differed from all other enzymes in that they were consistently higher in the SW than the LW(f) morph on day 5 on all diets. Al- 
though activities differed significantly between morphs only on the $100 \%$ diet, activities in the SW morph were significantly higher than in the LW(f) morph when data were pooled across all diets (ANOVA: $P<0.005$; no significant interaction between morph and diet; ANOVA: $P>0.1)$.

\subsection{AAT}

As was the case for most other enzymes, activities of AAT, an enzyme involved in amino acid catabolism, did not differ between morphs on day 0 (Figure 3 ). However, on day 5 , activities were significantly higher in the $L W(\mathrm{f})$ compared with the SW morph on the 100 and $25 \%+$ sucrose diets, but not on the $25 \%$ diet. Activities increased between day 0 and day 5 for each morph on each diet, except for the SW morph on the $100 \%$ diet (Figure 3).

\subsection{Activities of the $L W(h)$ morph}

Enzyme activities of the flightless LW(h) morph are presented in Table 1. The LW(h) morph is derived from the LW(f) morph by histolysis of flight muscles, and only a few of these individuals were produced in the present study. In 11 of 17 cases, fat body activities of this morph were intermediate between those of the $\mathrm{LW}(\mathrm{f})$ and SW morphs. In general, enzyme activities were closer to those of the flightless SW morph as opposed to the flight-capable $L W(f)$ morph. In seven cases, activities differed significantly $(P<0.05)$ or nearly significantly $(0.05<P<0.1)$ between the $L W(h)$ and $L W(f)$ but not the SW morph. By contrast, in only two cases did activities differ between the $\mathrm{LW}(\mathrm{h})$ and SW but not the LW(f) morph (Table 1).

\subsection{Fat body masses}

Fat body mass did not differ between morphs over all diets $\left[F_{(1,35)}=1.97 ; P=0.17\right]$ or on any diet considered separately (Table 2). However, there was a clear tendency for the $\mathrm{LW}(\mathrm{f})$ morph to contain a greater amount of fat body than the SW morph on the 100 and $25 \%$ diets.

\section{Discussion}

\subsection{General}

A number of studies have identified important physiological adaptations of morphs of wing-polymorphic species for flight vs. egg production (e.g., increased lipid levels in the dispersing morph; reviewed in Zera and Denno, 1997; Zera et al., 1998; Zera and Harshman, 2001). However, almost nothing has been published about the biochemical or metabolic bases of these physiological

Table 1. Specific activities of enzymes in the fat body of the flightless LW(h) morph of G. firmus with histolyzed flight muscles on day 5 of adulthood

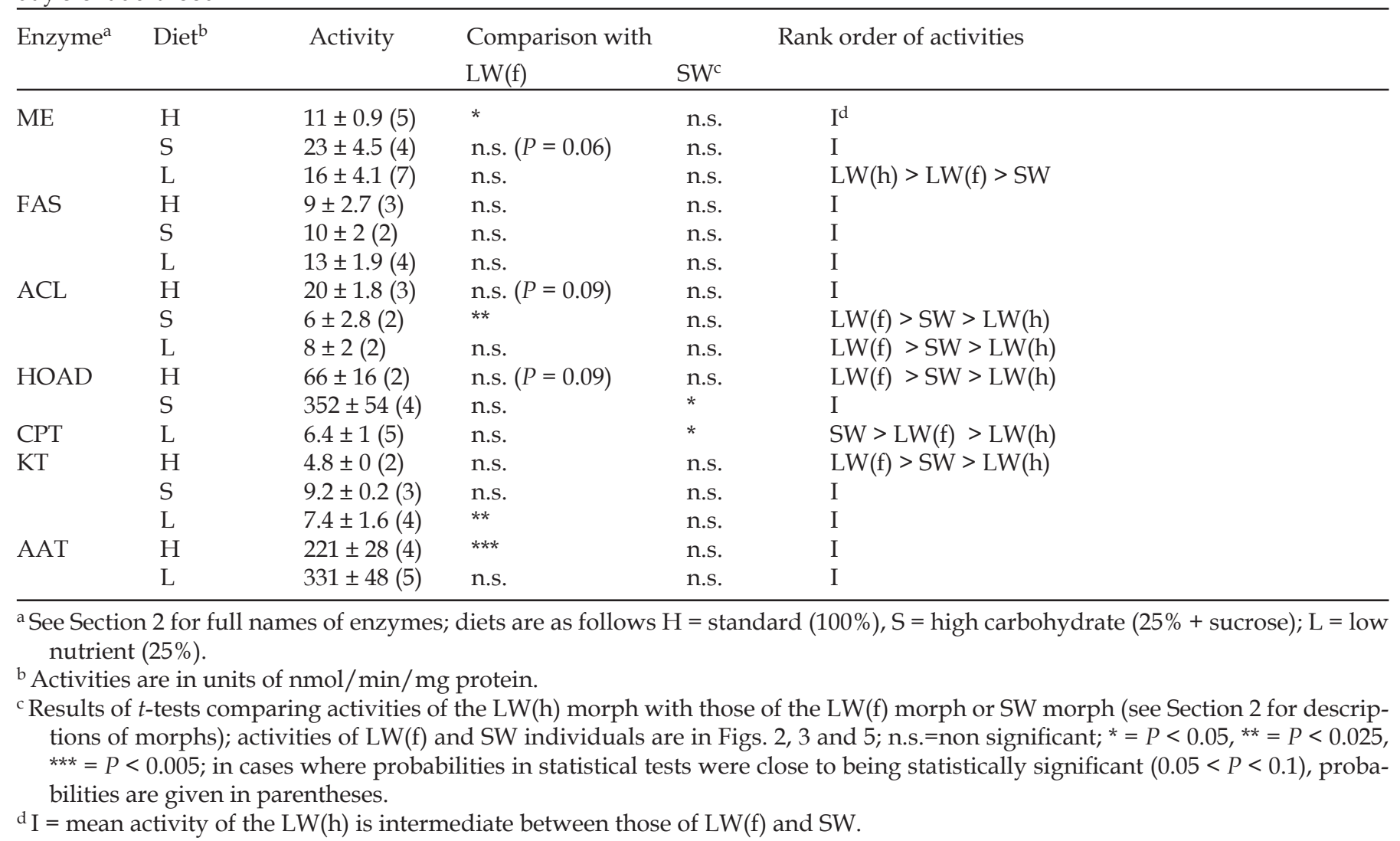


Table 2. Total fat body wet mass in the thorax and abdomen of wing and flight-muscle morphs of G. firmus fed various diets

\begin{tabular}{llll}
\hline Morph & $\begin{array}{l}\text { Diet } \\
\text { High (100\%) }\end{array}$ & Low (25\%) & $\begin{array}{l}\text { High } \\
\text { carbohydrate } \\
(25 \%+\text { sucrose })\end{array}$ \\
& & & \\
\hline LW(f) & & & $12.7 \pm 2.4(8)$ \\
Fat body & $28.0 \pm 2.7(7)^{a}$ & $15.5 \pm 3.2(6)$ & $593 \pm 31(8)$ \\
Whole body & $638 \pm 33(7)$ & $490 \pm 36(6)$ & \\
SW & & & $15.6 \pm 2.8(7)$ \\
Fat body & $21.6 \pm 3.1(7)$ & $10.0 \pm 2.6(7)$ & $513 \pm 33(7)$ \\
Whole body & $700 \pm 33(7)$ & $571 \pm 33(7)$ &
\end{tabular}

$\overline{{ }^{a} \text { Values are adjusted least-squares means of day } 5 \text { adults derived from }}$ ANCOVA with total wet body mass as the covariate.

adaptations (Zera et al., 1999). To our knowledge, the present study is the first documentation of adaptive differences in intermediary metabolism between morphs of a dispersal polymorphic insect species. The enzymes investigated have been extensively studied with respect to their role in lipid metabolism in insects. FAS and ACL catalyze key steps in the initial stages of de novo lipid biosynthesis (Municio et al. 1974; Storey and Bailey, 1978; Downer, 1985), while G-6-PDH, ME, and NADP+ ${ }^{+}$ IDH are important producers of NADPH, a key component of lipid biosynthesis (Downer, 1985). Activities of these five enzymes are strongly and positively correlated with rates of lipid biosynthesis (Walker and Bailey, 1970a, 1970b; Municio et al., 1974; Downer, 1985). Conversely, CPT transports fatty acids into the mitochondria where they are oxidized by enzymes of the $\beta$ oxidation pathway, two of which are HOAD and KT (Downer, 1985; Joanisse and Storey, 1996; Zera et al., 1999). Finally, transaminases such as AAT are important in converting amino acids into Krebs Cycle intermediates and subsequently into lipid (Steele, 1985).

\subsection{Differences in lipid biogenesis between morphs}

The most important finding of the present study was the substantially higher rate of lipid biosynthesis in the flight capable [LW(f)] vs. the obligately flightless (SW) morph of G. firmus during early adulthood (day 5) on the standard $(100 \%)$, and high carbohydrate $(25 \%+\mathrm{su}-$ crose) diets (Figure 2, Figure 3 and Figure 4). Strong support for this conclusion comes from the elevated activities of each of the five lipogenic enzymes, as well as the elevated rate of incorporation of ${ }^{14} \mathrm{C}$-acetate into total lipid on day 5 in the $\operatorname{LW}(\mathrm{f})$ morph on these two diets. Differences in lipogenesis between morphs were primarily due to differences in enzyme activity rather than to differences in the amount of lipid-biosynthesizing tissue (fat body). Morphs did not differ statistically in the quantity of fat body (Table 2), although there was a tendency for fat body quantity to be higher in the
LW(f) morph. The elevation in lipid biosynthesis from adult emergence to early adulthood in both the LW(f) and the SW morphs (Figure 4) is similar to developmental changes in lipid biosynthesis in other insects (Walker and Bailey, 1970b; Municio et al., 1974).

As expected, lipogensis was substantially lower on the low nutrient $(25 \%)$ diet: activities of the three NADPH-producing enzymes (IDH, ME, and G-6-PDH), activity of ACL, and incorporation of $\left[{ }^{14} \mathrm{C}\right]$-acetate into total lipid were low and barely increased, if at all, from day 0 to day 5. Moreover, enzyme activities and rate of lipid biosynthesis did not differ significantly between the morphs (Figure 2, Figure 3 and Figure 4). Reduced lipid biosynthesis on the low nutrient diet is not surprising since this diet does not provide sufficient nutrients to support growth in the LW(f) morph, and is barely able to support growth in the SW morph (Zera and Brink, 2000; Rooneem and Zera, unpublished data). As will be discussed in more detail below, these enzymological and radiotracer data are important since they allow us to draw preliminary conclusions concerning the biochemical processes responsible for the elevated lipid reserves documented previously in the $\mathrm{LW}(\mathrm{f})$ vs. SW morph of G. firmus (Zera and Larsen, 2001).

In most insects, triglyceride is, by far, the predominant lipid class by mass (Downer, 1985). In the orthopteran, Schistocerca gregaria, the main contributor to total lipid biosynthesis in adult males is triglyceride biosynthesis (Walker and Bailey, 1970a). However, in other insects, such as Ceratitis capitata and Acyrthosiphon pisum, $\left[{ }^{14} \mathrm{C}\right]$-acetate incorporation into phospholipid was greater than incorporation into triglyceride during adulthood, even though triglyceride is the most abundant lipid class during that time (Municio et al., 1974; de Renobales et al., 1990). We have not yet documented whether triglyceride biosynthesis is higher in adult LW(f) vs. SW G. firmus, although preliminary data strongly suggest that such is the case (Zhao and Zera, unpublished data)

\subsection{Activities of enzymes of lipid catabolism}

On two of three diets, activities of enzymes of lipid catabolism exhibited different patterns of variation compared with activities of biosynthetic enzymes. On the standard $(100 \%)$ diet, activities of two of three catabolic enzymes did not differ between morphs, in contrast to significant differences in activities of all lipogenic enzymes (Figure 2, Figure 3 and Figure 5). Conversely, on the low nutrient (25\%) diet, HOAD and KT both were significantly higher in the LW (f) compared with the SW morph, while activities of four of the five biosynthetic enzymes (FAS was the exception) did not differ between these morphs. On the high carbohydrate diet, activities of both lipogenic and catabolic enzymes were higher, in general, in the LW(f) compared with the SW morph on day 5. 
Although morphs differed in the activities of lipid catabolic enzymes, the extent to which these differences lead to morph-specific variation in lipid utilization remains uncertain. This uncertainty is due to the inconsistent pattern of variation for activities of catabolic enzymes, in contrast to the highly consistent patterns of variation for activities of biosynthetic enzymes. For example on the high sucrose or low nutrient diets, HOAD and KT differed significantly between morphs while CPT did not. On the standard diet, CPT activities differed between morphs while HOAD and KT activities did not (Figure 5). Finally, HOAD and KT activities were higher in the LW(f) vs. the SW morph on all diets, while the opposite was true for CPT activities. The reasons for these inconsistencies or their functional significance are unknown. Nor is it known which group of enzyme activities (HOAD and KT vs. CPT) is a better indicator of rate of lipid catabolism. Thus, it will be necessary to obtain additional enzymological data before reliable inferences can be drawn concerning differences between morphs in rates of lipid catabolism.

\subsection{The metabolic causes of differences in energy reserves be- tween morphs of G. firmus}

On each of the three diets studied, LW(f) females contain a greater amount of total lipid and triglyceride (30$38 \%$ ) than SW female G. firmus near the end of the first week of adulthood (Zera and Larsen, 2001). These differences in lipid and triglyceride levels between morphs are produced during adulthood and are negatively correlated with egg production in the morphs. Triglyceride is the major flight fuel of Gryllus, and species of this genus are capable of continuous, long-duration $(>6 \mathrm{~h})$ flight (Zera and Rankin, 1989; Zera et al., 1999). Thus, accumulation or retention of large quantities of triglyceride in the LW(f) morph appears to be an important adaptation for flight. The evolution of flightlessness in G. firmus appears to have involved modification of lipid metabolism leading to a reduction in lipid accumulation during early adulthood. This reduction, in turn, is potentially an important factor that allows a greater proportion of assimilated nutrients to be diverted into egg production. We have previously shown that lipid acquisition from the diet (= consumption $\times$ assimilation) is not greater in the $L W(f)$ morph compared with the SW morph during the first week of adulthood (Zera and Brink, 2000; Rooneem and Zera, unpublished data). Thus, differences between morphs in lipid biosynthesis and/or catabolism must cause the morph-specific differences in lipid reserves during early adulthood. Results obtained in the present study allow a preliminary assessment of the likely metabolic causes of these morphspecific differences.

On the standard diet, the greater lipid content of the LW(f) vs. the SW morph on day 5 of adulthood results from an increase in total lipid and triglyceride content of the LW(f) morph during the first five days of adulthood, coupled with no change in lipid content between these days in the SW morph (Zera and Larsen, 2001). These data suggest that the increased lipid level in the LW(f) morph results from a net increase in lipid biosynthesis compared with the SW morph (Zera and Larsen, 2001). The increased rate of de novo lipid biosynthesis, coupled with the increased activities of each of the five lipogenic enzymes in the $\mathrm{LW}(\mathrm{f})$ morph relative to the SW morph, are all consistent with this idea. Thus, variation in lipid biosynthesis alone may account for differences between the morphs in total lipid reserves on the standard diet during early adulthood.

On the $25 \%$ diet, by contrast, the greater amount of lipid and triglyceride in the LW(f) vs. SW morph on day 5 of adulthood results from a greater reduction in lipid content in the SW morph during the first five days of adulthood (Zera and Larsen, 2001). Given the equivalent rates of lipid biosynthesis in the morphs over these days on the $25 \%$ diet (Figure 4), variation in lipid catabolism likely plays the primary role in producing these differences in lipid levels between morphs on the $25 \%$ diet. Similarly, on the high sucrose diet, elevated total lipid and triglyceride contents in the LW(f) vs. SW morph on day 5 result from no change in lipid and triglcyeride content in the LW(f) morph over the first 5 days of adulthood coupled with a decrease in the concentration of these compounds in the SW morph during this time. Rates of lipid biogenesis, however, increased in both morphs between days 5 and 0 , although they increased to a greater degree in the LW(f) vs. the SW morph (Figure 4). These differences in lipid biosynthesis alone cannot account for the temporal changes in total lipid levels observed in the LW(f) and SW morphs on the high sucrose diet during the first five days of adulthood. Differences in lipid catabolism between morphs appear to act in concert with differences in biosynthesis to produce observed changes in total lipid and triglyceride on the high sucrose diet. A more rigorous assessement of the causes of morph-specific differences in lipid levels must await the results of future experiments on lipid catabolism which are currently in progress.

\subsection{Amino acid catabolism}

In insects, a substantial quantity of amino-acids are converted into lipid or are oxidized, in addition to being converted into protein (Clements, 1959; Downer, 1985; Steele, 1985). For example, Clements (1959) reported that $64 \%$ of radiolabeled glycine was oxidized, $24 \%$ was incorporated into fat, and $24 \%$ was incorporated into protein in the fat body of Schistocerca gregaria in vitro. The differential utilization of amino acids by $\mathrm{LW}(\mathrm{f})$ and SW morphs for energy, lipid biosynthesis, or vitellogenin 
biosynthesis could be a particularly important component of the trade-off between flight-capability (e.g. biosynthesis of flight fuel) and reproduction (e. g. biosynthesis of yolk protein). Various transaminases such as AAT (also called GPT) catalyze the conversion of amino acids into Krebs cycle intermediates which can subsequently be oxidized or converted into lipid or carbohydrate (Downer, 1985; Steele, 1985). AAT activity appears to be regulated by hormones than control amino acid metabolism and its interactions with carbohydrate and lipid metabolism (Steele, 1985). The specific activity of AAT in the fat body was significantly higher in the LW(f) vs. the SW morph fed the high carbohydrate, and especially fed the high nutrient diet. This result is consistent with the idea that the rate of oxidation or conversion of amino acids into lipid is higher in the $\mathrm{LW}(\mathrm{f})$ vs. the SW morph fed these diets. Radiotracer studies of amino acid metabolism will be required to more directly address this question. AAT also is elevated in histolyzing flight muscle of G. firmus, where it may be involved in the conversion of histolyzed protein into Krebs cycle intermediates (Zera et al., 1999).

\subsection{Enzyme activities in the $L W(h)$ morph}

Two flightless morphs (LW(h) and SW) exist in G. firmus, and are produced by different physiological mechanisms operating during different stages of the life cycle (see Section 2; Zera et al., 1997). An interesting question with respect to the evolution of flightlessness, is the extent to which similar aspects of physiology are altered in these flightlessness morphs (see extensive discussion in Zera et al., 1997). Previous studies have shown that the $L W(h)$ morph is very similar to the SW morph, and that both of these flightless morphs differ from the flight capable $L W(f)$ morph to a similar degree, in a wide variety of traits such as ovarian growth, hemolymph juvenile hormone and ecdyteroid titers, various indices of nutrient acquisition and allocation, and levels of energy reserves on some diets (Zera et al., 1997; Zera and Brink, 2000; Zera and Cisper, 2001; Zera and Bottsford, 2001; Zera and Larsen, 2001). However, the picture is less consistent with respect to enzyme activities of flight muscles of the three morphs (Zera et al., 1999; Table 1). Activities of flight-muscle enzymes involved in lipid, carbohydrate and amino acid catabolism of the flightless $L W(h)$ morph were typically intermediate between those of the flight-capable LW(f) and flightless SW morphs and tended to be more similar to activities in the flightless SW morph. However a number of exceptions was noted. In the present study, only a few $\mathrm{LW}(\mathrm{h})$ females were produced in the LW-selected line and, thus, only a restricted comparison could be undertaken between the two flightless and the flight-capable morphs of G. firmus (Table 1). In most cases, activities of enzymes of lipid metabolism in the fat bodies of the
LW(h) morph were intermediate between those of the LW(f) and SW morphs, and tended to be more similar to the SW morph (Results, Table 1). Thus, a roughly similar pattern of variation was observed among morphs with respect to enzyme activities of flight muscles (Zera et al., 1999) and fat bodies (Table 1).

\subsection{Summary}

We have documented consistent differences in in vitro activities of lipogenic enzymes and in vivo rates of lipogenesis between the flight-capable and the obligately flightless morphs of G. firmus. Morph-specific differences in enzyme activities and rates of lipogenesis provide information on potential biochemical causes of the difference between morphs in lipid reserves, which appears to be a key component of the trade-off between flight capability and reproduction in this species. This study represents an important step in understanding how intermediary metabolism has been modified during the evolution of morphs adapted for flight vs. reproduction.

\section{Acknowledgments}

We thank A. Benner for maintenance of cricket colonies. This work was supported by the National Science Foundation (IBN-9808249). Z. Zhao was supported in part by a Fellowship from the Peoples' Republic of China.

\section{References}

Beenakkers, A. M. T., 1969. Carbohydrate and fat as a fuel for insect flight. A comparative study. Journal of Insect Physiology 15, pp. 353-361.

Beenakkers, A. T. M., Van Der Horst, D. J., and Van Marrewijk, W. J. A., 1985. Biochemical processes directed to flight muscle metabolism. In: Kerkut, G. A., and Gilbert, L. I., Editors, 1985. Comprehensive Insect Physiology, Biochemistry, and Pharmacology 10, Pergamon, New York, pp. 451-486.

Bergmeyer, H. U., 1974. Methods of Enzymatic Analysis, Academic Press, New York.

Bieber, L. L., Abraham, T., and Helmrath, T., 1972. A rapid spectrophotometric assay for carnitine palmitoyl transferase. Analytical Biochemistry 50, pp. 509-518.

Buckner, J. S., and Kolattukudy, P. E., 1976. One-step purification and properties of a two-peptide fatty acid synthase from the uropygial gland of the goose. Biochemistry 15, pp. 1948-1957.

Candy, D. J., 1989. Utilization of fuels by the flight muscles. In: Goldsworthy, G. J., and Wheeler, C. H., Editors, 1989. Insect Flight, CRC Press, Boca Raton, pp. 305-319.

Cisper, G., Zera, A. J., and Borst, D. W., 2000. Juvenile hormone titer and morph-specific reproduction in the wingpolymorphic cricket, Gryllus firmus. Journal of Insect Physiology 46, pp. 585-596.

Clements, A. N., 1959. Studies on the metabolism of locust fat body. Journal of Experimental Biology 36, pp. 665-675. 
de Renobales, M., Cripps, C., and Kinsey, M., 1990. Lipid biosynthesis in adult Acyrthosiphon pisum: effect of age and symbiont population. Archives of Insect Biochemistry and Physiology 14, pp. 85-92.

Dingle, H., 1996. Migration: The Biology of Life on the Move, Oxford University Press, Oxford.

Downer, R. G. H., 1985. Lipid metabolism. In: Kerkut, G. A., and Gilbert, L. I., Editors, 1985. Comprehensive Insect Physiology, Biochemistry and Pharmacology, Pergamon, Oxford, pp. 77-114.

Geer, B. W., and Perille, T. J., 1977. Effects of dietary sucrose and environmental temperature on fatty acid synthesis in Drosophila melanogaster. Insect Biochemistry 7, pp. 371-379.

Gunn, A., and Gatehouse, G., 1987. The influence of larval phase on metabolic reserves, fecundity and lifespan of the African armyworm moth, Spodoptera exempta (Walker) (Lepidoptera: Noctuidae). Bulletin of Entomological Research 77, pp. 651-660.

Harrison, R. G., 1980. Dispersal polymorphisms in insects. Annual Review of Ecology and Systematics 11, pp. 95-118.

Joanisse, D. R., and Storey, K. B., 1996. Fatty acid content and enzymes of fatty acid metabolism in overwintering coldhardy gall insects. Physiological Zoology 69, pp. 1079-1095.

Mole, S., and Zera, A., 1993. Differential allocation of resources underlies the dispersal-reproduction trade-off in the wingdimorphic cricket, Gryllus rubens. Oecologia 93, pp. 121-127.

Municio, A. M., Odriozola, J. M., Albarsanz, P., Ramos, J. A., and Relano, E., 1974. Lipogenesis from $\left[{ }^{14} \mathrm{C}\right]$-acetate during development of Ceratitis capitata. Insect Biochemistry 4, pp. 401-409.

Newanze, K. F., Maskarinec, J. K., and Hopkins, T. L., 1976. Lipid composition of the normal and flight forms of adult cowpea weevils, Callosobruchus maculatus. Journal of Insect Physiology 22, pp. 897-899.

Roff, D. A., 1986. The evolution of wing dimorphism in insects. Evolution 40, pp. 1009-1020.

Stoscheck, C. M., 1990. Quantitation of protein. Methods in Enzymology 182, pp. 60-63.

Steele, J. H., 1985. Control of metabolic processes. In: Kerkut, G. A., and Gilbert, L. I., Editors, 1985. Comprehensive Insect Biochemistry, Physiology and Pharmacology, Pergamon, Oxford, pp. 99-146.

Storey, K. B., and Bailey, E., 1978. Intracellular distribution of enzymes associated with lipogenesis and gluconeogenesis in the fat body of the adult cockroach, Periplaneta. Insect Biochemistry 8, pp. 125-131.

Uvarov, B., 1966. Grasshoppers and Locusts 1, Cambridge University Press, London.

Veazy, J. N., Kay, C. A. R., Walker, T. J., and Whitcomb, W. H., 1976. Seasonal abundance, sex ratio, and macroptery of field crickets in northern Florida. Annals of the Entomological Society of America 69, pp. 374-380.

Walker, P. R., and Bailey, E., 1970. Metabolism of glucose, trehalose, citrate, acetate, and palmitate by the male desert locust during adult development. Journal of Insect Physiology 16, pp. 499-509.
Walker, P. R., and Bailey, E., 1970. Changes in enzymes associated with lipogenesis during development of the adult male desert locust. Journal of Insect Physiology 16, pp. 679-690.

Zera, A. J., and Bottsford, J., 2001. The endocrine-genetic basis of life-history variation: the relationship between the ecdysteroid titer and morph-specific reproduction in the wing-polymorphic cricket Gryllus firmus. Evolution 55, pp. 538-549.

Zera, A. J., and Brink, T., 2000. Nutrient absorption and utilization by wing and flight muscle morphs of the cricket Gryllus firmus: implications for the trade-off between flight capability and early reproduction. Journal of Insect Physiology 46, pp. 1207-1218.

Zera, A. J., and Cisper, G., 2001. Genetic and diurnal variation in the juvenile hormone titer in a wing-polymorphic cricket: implications for the evolution of life histories and dispersal. Physiological and Biochemical Zoology 74, pp. 293-306

Zera, A. J., and Denno, R. F., 1997. Physiology and ecology of dispersal polymorphism in insects. Annual Review of Entomology 42, pp. 207-231.

Zera, A. J., Larsen, A., 2001. The metabolic basis of life history variation: genetic and phenotypic differences in lipid reserves among life history morphs of the wing-polymorphic cricket, Gryllus firmus. Journal of Insect Physiology, in press.

Zera, A. J., and Huang, Y., 1999. Evolutionary endocrinology of juvenile hormone esterase: functional relationship with wing polymorphism in the cricket, Gryllus firmus. Evolution 53, pp. 837-847.

Zera, A. J., and Harshman, L. G., 2001. Physiology of life history trade-offs in animals. Annual Review of Ecology and Systematics 32, pp. 95-126.

Zera, A. J., Mole, S., and Rokke, K., 1994. Lipid, carbohydrate and nitrogen content of long- and short-winged Gryllus firmus: implications for the physiological cost of flight capability. Journal of Insect Physiology 40, pp. 1037-1044.

Zera, A. J., Potts, J., and Kobus, K., 1998. The physiology of life history trade-offs: experimental analysis of a hormonallyinduced life history trade-off in Gryllus assimilis. American Naturalist 152, pp. 7-23.

Zera, A. J., and Rankin, M. A., 1989. Wing dimorphism in Gryllus rubens: genetic basis of morph determination and fertility differences between morphs. Oecologia 80, pp. 249-255.

Zera, A. J., Sall, J., and Grudzinski, K., 1997. Flight-muscle polymorphism in the cricket Gryllus firmus: muscle characteristics and their influence on the evolution of flightlessness. Physiological Zoology 70, pp. 519-529.

Zera, A. J., Sall, J., and Otto, K., 1999. Biochemical aspects of flight and flightlessness in Gryllus: flight fuels, enzyme activities, and electrophoretic profiles of flight muscles from flight-capable and flightless morphs. Journal of Insect Physiology 45, pp. 275-285. 